\title{
Residue Collection on Oral Structures
}

National Cancer Institute

\section{Source}

National Cancer Institute. Residue Collection on Oral Structures. NCI Thesaurus. Code C127211.

A finding of residue collection on oral structures after swallowing. 